\title{
Generalized Minimum Variance Control for MDOF Structures under Earthquake Excitation
}

\author{
Lakhdar Guenfaf and Mohamed Azira \\ LSEI Laboratory, USTHB University, BP 32 El Alia, Bab Ezzouar, 16111 Algiers, Algeria \\ Correspondence should be addressed to Mohamed Azira; mohamed.azira@yahoo.fr
}

Received 28 March 2016; Revised 24 June 2016; Accepted 10 July 2016

Academic Editor: William MacKunis

Copyright (C) 2016 L. Guenfaf and M. Azira. This is an open access article distributed under the Creative Commons Attribution License, which permits unrestricted use, distribution, and reproduction in any medium, provided the original work is properly cited.

Control of a multi-degree-of-freedom structural system under earthquake excitation is investigated in this paper. The control approach based on the Generalized Minimum Variance (GMV) algorithm is developed and presented. Our approach is a generalization to multivariable systems of the GMV strategy designed initially for single-input-single-output (SISO) systems. KanaiTajimi and Clough-Penzien models are used to generate the seismic excitations. Those models are calculated using the specific soil parameters. Simulation tests using a 3DOF structure are performed and show the effectiveness of the control method.

\section{Introduction}

During the last decades, there have been many attempts in the field of structural control to develop new algorithms according to the increasing size and flexibility of building structures. This is done especially for multi-degree-of-freedom (MDOF) structures subjected to strong vibrations. A MDOF structure can be considered as a large-scale system with interconnected subsystems, which are story units. Therefore, control techniques initially designed for SDOF structures cannot be directly applied to MDOF structures. The problem of interconnection between story units and the structural proprieties of the building are considered as a whole system and must be addressed. The interconnection effects can also be introduced in control law formulation or considered as external disturbances to be compensated by control actions. Another problem encountered in MDOF structural control is the number and location of actuators. In fact it seems to be more efficient to place an actuator in each story unit, but the cost of implementation may be very expensive.

Several structural models have been investigated in the literature for an active control perspective. Indeed, many researchers have used an active control strategy based on state-space model to develop and design a controller for structural vibration [1-6]. Nonlinear model has been used and presented for Stochastic Optimal Control of Structural
Systems [1, 7]. Saaed Alqado et al. [8] have developed five methods for structural identification approach, specifically ARX, ARMAX, BJ, OE, and state-space models, and have implemented them for the identification process. Furthermore, the paper shows that the ARMAX and the output error models have indicated an excellent performance to predict the mathematical models of vibration's propagation in the building. Also, it has been shown by Guenfaf and Azira [9] that the ARMAX model can give an interesting representation of the system for a digital control perspective. In this case the system is characterized as stochastic process described by a linear model subjected to external disturbances.

Vigorous researches on structural control have given more interesting solutions [10-12]; some of them have already been adopted in actual building structures. Guenfaf et al. [13] have presented GMV algorithm based on ARMAX model of SDOF structure with introducing Kanai-Tajimi and Clough-Penzien seismic excitation within the structural model. The results show that the relative displacement of the structure and the control effort are significantly reduced. Lei et al. [14] have proposed an algorithm for the decentralized structural control of tall shear-type buildings under unknown earthquake excitation. A decentralized control algorithm based on the instantaneous optimal control scheme has been developed with limited measurements of structural absolute acceleration responses. The interconnection effect 
between adjacent substructures has been treated as "additional unknown disturbances" at substructural interfaces to each substructure. However, the control algorithm is based on the minimization of some cost functions such as linear quadratic regulator which requires a solution of the Riccati equation that is subjected to a boundary condition at the terminal time. That leads to a suboptimal solution. So, in such perturbated systems, the controller performances and robustness may be weak [15].

The purpose of this paper is to develop a control strategy applied to an earthquake excited 3DOF structure. This algorithm attempts to minimize a generalized cost function including variance of both output and control effort. For this purpose a specific model of the system to be controlled and its environment will be developed.

The GMV algorithm has been widely studied in the literature. It was introduced by Clarke $[16,17]$ as an extended version of the Minimum Variance (MV) algorithm initially developed by Åström [18].

The paper is organized as follows. Section 2 deals with the development of the dynamic model of the structure, while Section 3 deals with presentation of the MIMO ARMAX model. The GMV algorithm is introduced in Section 4. The seismic excitation models are presented in Section 5. In Section 6, simulation results show the effectiveness of the developed algorithms. Finally, some conclusions are given.

\section{Dynamical Model of a Multi-Degree-of-Freedom Structure}

The purpose of this section is to formulate dynamical equations of motion of a multi-degree-of-freedom structure under seismic excitation. Figure 1(a) is a schematic representation of the structure. It is a multistory building with active tendon controllers in each story unit. In order to establish the dynamical model, the following assumptions are considered [19]:

(1) Each story is supposed to be a lumped mass in the girder.

(2) The two vertical axes between two adjacent floors are weightless and inextensible in the vertical direction.

Figure $1(\mathrm{~b})$ is a representation of the dynamic force equilibration at $i$ th story unit, which can be written as

$$
\begin{aligned}
& f_{I_{i}}(t)+f_{A_{i}}(t)+f_{E_{i}}(t)-f_{A_{i+1}}(t)-f_{E_{i+1}}(t) \\
& \quad=u_{i}(t)-u_{i+1}(t),
\end{aligned}
$$

where

$f_{I_{i}}(t)$ is the inertial force of the mass $m_{i}$

$$
f_{I_{i}}(t)=m_{i} \ddot{x}_{i}^{t}(t)
$$

$f_{A_{i}}(t)$ is the damping force of $i$ th story

$$
f_{A_{i}}(t)=c_{i}\left(\dot{x}_{i}(t)-\dot{x}_{i-1}(t)\right)
$$

$f_{E_{i}}(t)$ is the elastic force of $i$ th story

$$
f_{E_{i}}(t)=k_{i}\left(x_{i}(t)-x_{i-1}(t)\right)
$$

where relative displacement is $x_{i}(t)$.

$u_{i}(t)$ is the control force from the controller installed between $(i-1)$ th story and $i$ th story.

Absolute displacement $x_{i}^{t}(t)$ is defined as

$$
x_{i}^{t}(t)=x_{i}(t)+x_{g}(t)
$$

where $x_{g}(t)$ is the ground motion.

$i$ th story unit is characterized by its characteristic parameters. In this system, it is assumed that the structural mass, $m_{i}$, and the elastic stiffness, $k_{i}$, have been concentrated in floors and columns, respectively. Internal viscous damping, $c_{i}$, is also a parameter that describes the structural behaviour.

Substituting (2), (3), (4), and (5) into (1), we obtain

$$
\begin{array}{r}
m_{i}\left(\ddot{x}_{i}+\ddot{x}_{g}\right)+c_{i}\left(\dot{x}_{i}-\dot{x}_{i-1}\right)+k_{i}\left(x_{i}-x_{i-1}\right) \\
-c_{i+1}\left(\dot{x}_{i+1}-\dot{x}_{i}\right)-k_{i+1}\left(x_{i+1}-x_{i}\right)=u_{i}-u_{i+1} \\
i=\overline{1, n}
\end{array}
$$

where $c_{n+1}=0, k_{n+1}=0, x_{0}=0, x_{n+1}=0, u_{n+1}=0$, and $\ddot{x}_{g}(t)$ represents the ground acceleration.

Equation (6) can be written in matrix form as

$$
M \ddot{X}(t)+C \dot{X}(t)+K X(t)=L U(t)-M I_{v} \ddot{x}_{g}(t),
$$

where $X^{T}(t)=\left[\begin{array}{llll}x_{1}(t) & x_{2}(t) & \cdots & x_{n}(t)\end{array}\right]$ is the structural displacement vector, $U^{T}(t)=\left[\begin{array}{llll}u_{1}(t) & u_{2}(t) & \cdots & u_{n}(t)\end{array}\right]$ control vector, $M$ is the $(n \times n)$ mass matrix of the structure, $C$ is the $(n \times n)$ damping matrix of the structure, $K$ is the $(n \times n)$ stiffness matrix of the structure, $L$ is the $(n \times 1)$ matrix indicating the location of actuators, and $I_{v}=\left[\begin{array}{llll}1 & 1 & \cdots & 1\end{array}\right]^{T}$ unity vector of dimension $(n \times 1)$.

\section{ARMAX Model of the Structure}

We are interested in this section to derive the discrete ARMAX model of the MDOF structure. Consider the state-space equation of the MDOF structure which can be obtained from (7) by choosing $Z^{T}(t)=\left[\begin{array}{lll}Z_{1}^{T}(t) & Z_{2}^{T}(t)\end{array}\right]=$ $\left[X^{T}(t) \dot{X}^{T}(t)\right]$ as a state vector:

$$
\begin{aligned}
& \dot{Z}(t)=A Z(t)+B U(t)+E \ddot{x}_{g}(t), \\
& Y(t)=D Z(t),
\end{aligned}
$$

where $A=\left[\begin{array}{cc}\stackrel{0}{=} & I \\ -M^{-1} K & -M^{-1} C\end{array}\right]$ of dimension $(2 n \times 2 n), B=$ $\left[\begin{array}{c}\stackrel{0}{=} \\ M^{-1} L\end{array}\right]$ of dimension $(2 n \times n), E=\left[\frac{0}{I_{v}}\right]$ of dimension $(2 n \times 1)$, $D=\left[\begin{array}{ll}I & \underline{\underline{n}} \\ \underline{\underline{0}} & \underline{\underline{0}}\end{array}\right]$ of dimension $(2 n \times 2 n), I$ identity matrix of 


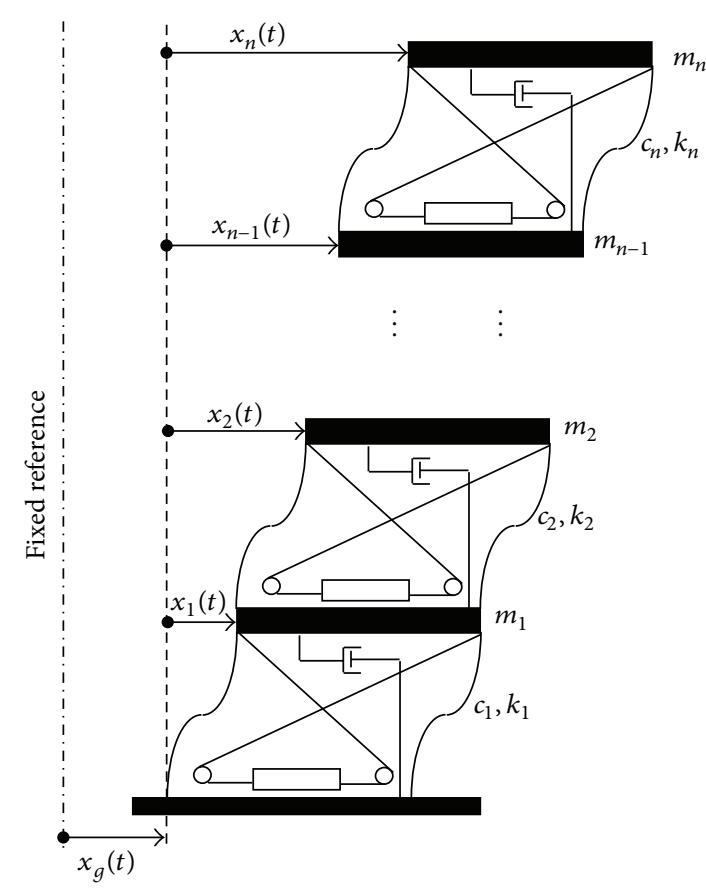

(a)

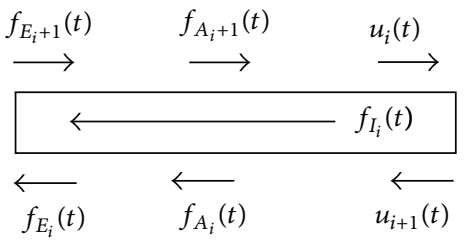

(b)

FIGURE 1: Schematic representation of a multi-degree-of-freedom structure under seismic excitation. (a) Motion of the structure; (b) forces equilibrium of $i$ th story unit.

dimension $(n \times n), \underline{0}$ null matrix of dimension $(n \times n)$, and $\underline{0}$ null vector of dimension $(n \times 1)$.

The digital control of the system needs the knowledge of the discrete representation model. Thus, the continuous model can be written in the following form [20-22]:

$$
\begin{gathered}
{\left[\begin{array}{ccc}
A_{11}\left(q^{-1}\right) & \cdots & A_{1 n}\left(q^{-1}\right) \\
\vdots & \ddots & \vdots \\
A_{n 1}\left(q^{-1}\right) & \cdots & A_{n n}\left(q^{-1}\right)
\end{array}\right] X(t)} \\
=\left[\begin{array}{ccc}
B_{11}\left(q^{-1}\right) & \cdots & B_{1 n}\left(q^{-1}\right) \\
\vdots & \ddots & \vdots \\
B_{n 1}\left(q^{-1}\right) & \cdots & B_{n n}\left(q^{-1}\right)
\end{array}\right] U(t) \\
+\left[\begin{array}{ccc}
C_{11}\left(q^{-1}\right) & \cdots & C_{1 n}\left(q^{-1}\right) \\
\vdots & & \ddots \\
C_{n 1}\left(q^{-1}\right) & \cdots & C_{n n}\left(q^{-1}\right)
\end{array}\right] \underline{e}(t),
\end{gathered}
$$

where $X(t)=\left[\begin{array}{lll}x_{1}(t) & \cdots & x_{n}(t)\end{array}\right]^{T}$ is the $n \times 1$ output vector, $U(t)=\left[\begin{array}{lll}u_{1}(t) & \cdots & u_{n}(t)\end{array}\right]^{T}$ is the $n \times 1$ input vector, $\underline{e}(t)=$ $\left[\begin{array}{llll}e_{1}(t) & \cdots & e_{n}(t)\end{array}\right]^{T}$ is the $n \times 1$ zero-mean white noise vector with covariance matrix $E\left[e(t) e^{T}(t)\right]=r * I, A_{i i}\left(q^{-1}\right)=1+$ $\sum_{l=1}^{n_{i i}} a_{i i_{l}} q^{-l}, A_{i j}\left(q^{-1}\right)=\sum_{l=1}^{n_{i j}} a_{i j_{l}} q^{-l}, B_{i j}\left(q^{-1}\right)=q^{-d_{i j}} \sum_{l=1}^{m_{i j}} b_{i j} q^{-l}$, $C_{i i}\left(q^{-1}\right)=1+\sum_{l=1}^{n c_{i i}} c_{i i} q^{-l}, C_{i j}\left(q^{-1}\right)=\sum_{l=1}^{n c_{i j}} c_{i j} q^{-l}$, for $i=\overline{1, n}$, $j=\overline{1, n}, d_{i j} \geq 0, q^{-1}$ shift operator defined as $q^{-1} x_{i}(t+1)=$ $x_{i}(t)$.

3.1. Multivariable Model. We intend in this section to derive the complete multivariable ARMAX model of the MDOF structure without neglecting the coupling between stories. We can perform this calculation using the equation of motion of the structural system. Consider (6) which can be rewritten in the following form:

$$
\begin{aligned}
m_{i} \ddot{x}_{i} & +\left(c_{i}+c_{i+1}\right) \dot{x}_{i}+\left(k_{i}+k_{i+1}\right) x_{i}-c_{i} \dot{x}_{i-1}-k_{i} x_{i-1} \\
& -c_{i+1} \dot{x}_{i+1}-k_{i+1} x_{i+1}=u_{i}-u_{i+1}-m_{i} \ddot{x}_{g} .
\end{aligned}
$$

Now applying the Laplace transform to this equation,

$$
\begin{aligned}
\left(s^{2}+\right. & \left.\frac{c_{i}+c_{i+1}}{m_{i}} s+\frac{k_{i}+k_{i+1}}{m_{i}}\right) X_{i}(s) \\
& -\left(\frac{c_{i}}{m_{i}} s+\frac{k_{i}}{m_{i}}\right) X_{i-1}(s) \\
& -\left(\frac{c_{i+1}}{m_{i}} s+\frac{k_{i+1}}{m_{i}}\right) X_{i+1}(s) \\
= & \frac{1}{m_{i}} U_{i}(s)-\frac{1}{m_{i}} U_{i+1}(s)-\ddot{X}_{g}(s) .
\end{aligned}
$$

Thus, we can deduce the continuous ARMAX model given in the following:

$$
\bar{A}(s) X(s)=\bar{B}(s) U(s)+\bar{C}(s) I_{v} \ddot{X}_{g}(s),
$$


where

$$
\begin{aligned}
& \bar{A}(s)=\left[\begin{array}{cccc}
\bar{A}_{11}(s) & \bar{A}_{12}(s) & & 0 \\
\bar{A}_{21}(s) & \bar{A}_{22}(s) & \bar{A}_{23}(s) & \\
& & \ddots & \\
0 & & \bar{A}_{n(n-1)}(s) & \bar{A}_{n n}(s)
\end{array}\right], \\
& \bar{B}(s)=\left[\begin{array}{cccc}
\bar{B}_{11}(s) & \bar{B}_{12}(s) & & 0 \\
& \bar{B}_{22}(s) & \bar{B}_{23}(s) & \\
& & \ddots & \\
0 & & \bar{B}_{n(n-1)}(s) & \bar{B}_{n n}(s)
\end{array}\right], \\
& \bar{C}(s)=\left[\begin{array}{ccc}
\bar{C}_{11}(s) & & 0 \\
& \ddots & \\
0 & & \bar{C}_{n n}(s)
\end{array}\right], \\
& X(s)=\left[\begin{array}{lll}
X_{1}(s) & \cdots & X_{n}(s)
\end{array}\right]^{T}, \\
& U(s)=\left[\begin{array}{lll}
U_{1}(s) & \cdots & U_{n}(s)
\end{array}\right]^{T}
\end{aligned}
$$

with $\bar{A}_{i i}(s)=s^{2}+\left(\left(c_{i}+c_{i+1}\right) / m_{i}\right) s+\left(k_{i}+k_{i+1}\right) / m_{i}, \bar{A}_{i(i-1)}(s)=$ $-\left(\left(c_{i} / m_{i}\right) s+k_{i} / m_{i}\right), \bar{A}_{i(i+1)}(s)=-\left(\left(c_{i+1} / m_{i}\right) s+k_{i+1} / m_{i}\right)$, and $\bar{B}_{i i}(s)=1 / m_{i}, \bar{B}_{i(i+1)}(s)=-1 / m_{i}, \bar{C}_{i i}(s)=-1$.

To obtain the discrete ARMAX model, we use (11) written as

$$
\begin{aligned}
X_{i}(s) & +\frac{\bar{A}_{i(i-1)}(s)}{\bar{A}_{i i}(s)} X_{i-1}(s)+\frac{\bar{A}_{i(i+1)}(s)}{\bar{A}_{i i}(s)} X_{i+1}(s) \\
= & \frac{\bar{B}_{i i}(s)}{\bar{A}_{i i}(s)} U_{i}(s)+\frac{\bar{B}_{i(i+1)}(s)}{\bar{A}_{i i}(s)} U_{i+1}(s) \\
& +\frac{\bar{C}_{i i}(s)}{\bar{A}_{i i}(s)} \ddot{X}_{g}(s)
\end{aligned}
$$

Using discretization methods, we deduce the discrete form of (14):

$$
\begin{aligned}
x_{i}(t) & +\frac{\bar{A}_{i(i-1)}\left(q^{-1}\right)}{\bar{A}_{i i}\left(q^{-1}\right)} x_{i-1}(t)+\frac{\bar{A}_{i(i+1)}\left(q^{-1}\right)}{\bar{A}_{i i}\left(q^{-1}\right)} x_{i+1}(t) \\
= & \frac{\bar{B}_{i i}\left(q^{-1}\right)}{\bar{A}_{i i}\left(q^{-1}\right)} u_{i}(t)+\frac{\bar{B}_{i(i+1)}\left(q^{-1}\right)}{\bar{A}_{i i}\left(q^{-1}\right)} u_{i+1}(t) \\
& +\frac{\bar{C}_{i i}\left(q^{-1}\right)}{\bar{A}_{i i}\left(q^{-1}\right)} \ddot{x}_{g}(t) .
\end{aligned}
$$

The discrete multivariable ARMAX model is then obtained. It is given by

$$
\bar{A}\left(q^{-1}\right) X(t)=\bar{B}\left(q^{-1}\right) U(t)+\bar{C}\left(q^{-1}\right) I_{v} \ddot{x}_{g}(t),
$$

where

$$
\begin{aligned}
& \bar{A}\left(q^{-1}\right)
\end{aligned}
$$

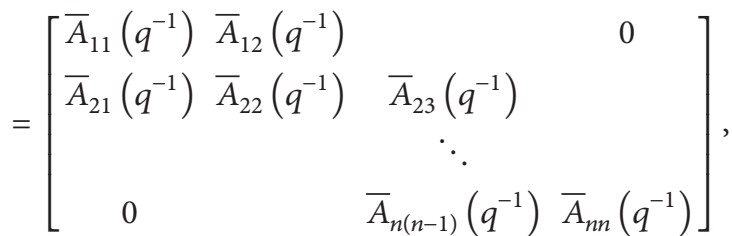

$$
\begin{aligned}
& \bar{B}\left(q^{-1}\right) \\
& =\left[\begin{array}{cccc}
\bar{B}_{11}\left(q^{-1}\right) & \bar{B}_{12}\left(q^{-1}\right) & & 0 \\
& \bar{B}_{22}\left(q^{-1}\right) & \bar{B}_{23}\left(q^{-1}\right) & \\
& & \ddots & \\
0 & & \bar{B}_{n(n-1)}\left(q^{-1}\right) & \bar{B}_{n n}\left(q^{-1}\right)
\end{array}\right], \\
& \bar{C}\left(q^{-1}\right)=\left[\begin{array}{ccc}
\bar{C}_{11}\left(q^{-1}\right) & & 0 \\
& \ddots & \\
0 & & \bar{C}_{n n}\left(q^{-1}\right)
\end{array}\right] .
\end{aligned}
$$

Remark 1. We can introduce here the seismic excitation model in the derivation of the multivariable ARMAX model. By considering the seismic excitation as a filtered white noise, we follow the same calculations as done in Section 3.1, to obtain the discrete multivariable ARMAX model of the structure under a specified excitation model [23].

\section{Generalized Minimum Variance Control Algorithm}

The Generalized Minimum Variance (GMV) algorithm was introduced by Clarke $[16,17]$ to control nonminimum phase systems. It is an extension of the Minimum Variance algorithm [18] which, by choosing a certain performance criterion and a certain model of the controlled system and its perturbations, attempts to minimize the variance of the output. A generalization of the GMV algorithm for multiinput-multi-output (MIMO) systems has been proposed in the context of self-tuning control [24-26]. The controlled system in this case is assumed to be described by a linear vector difference equation including a moving average of white noise.

A Generalized Minimum Variance strategy for multivariable systems will be now presented. Consider the system described by the linear vector difference equation (multivariable ARMAX model):

$$
A\left(q^{-1}\right) \underline{y}(t)=q^{-d} B\left(q^{-1}\right) \underline{u}(t)+C\left(q^{-1}\right) \underline{e}(t),
$$

where $y(t) n \times 1$ output vector, $\underline{u}(t) n \times 1$ input vector, $\underline{e}(t) n \times 1$ zero-mean white noise vector with covariance $E\left[e(t) e^{T}(t)\right]=$ $r, d \geq 0$ is the smallest time delay of the system [20], $A\left(q^{-1}\right)=$ $I+A_{1} q^{-1}+\cdots+A_{n_{a}} q^{-n_{a}}, B\left(q^{-1}\right)=B_{1} q^{-1}+\cdots+B_{n_{b}} q^{-n_{b}}$, 
$B_{1}$ is nonsingular, and $C\left(q^{-1}\right)=I+C_{1} q^{-1}+\cdots+C_{n_{c}} q^{-n_{c}}$, where

$$
\begin{aligned}
A_{i} & =\left[\begin{array}{ccc}
A_{11}\left(q^{-1}\right) & \cdots & A_{1 n}\left(q^{-1}\right) \\
\vdots & \ddots & \vdots \\
A_{n 1}\left(q^{-1}\right) & \cdots & A_{n n}\left(q^{-1}\right)
\end{array}\right], \\
B_{i} & =\left[\begin{array}{ccc}
B_{11}\left(q^{-1}\right) & \cdots & B_{1 n}\left(q^{-1}\right) \\
\vdots & \ddots & \vdots \\
B_{n 1}\left(q^{-1}\right) & \cdots & B_{n n}\left(q^{-1}\right)
\end{array}\right], \\
C_{i} & =\left[\begin{array}{ccc}
C_{11}\left(q^{-1}\right) & \cdots & C_{1 n}\left(q^{-1}\right) \\
\vdots & \ddots & \vdots \\
C_{n 1}\left(q^{-1}\right) & \cdots & C_{n n}\left(q^{-1}\right)
\end{array}\right] .
\end{aligned}
$$

We can summarize the basic assumptions on the system in the following:

The number of outputs is equal to the number of inputs.

$B_{1}$ is nonsingular.

The criterion to be minimized is

$$
\begin{aligned}
J= & E\left[\left\|P \underline{y}(t+d+1)-R_{w} \underline{w}(t+d+1)\right\|^{2}\right. \\
& \left.+\left\|Q_{m}^{\prime} \underline{u}(t)\right\|^{2}\right],
\end{aligned}
$$

where $E$ is expected value, $\underline{w}(t+d+1)$ is the $n \times 1$ vector defining the reference signal, $P, R_{w}$, and $Q_{m}^{\prime}$ are weighing polynomial matrices of dimension $n \times n$ each, and \| \| vectorial norm is defined as $\|V\|^{2}=V^{T} V$.

As in the monovariable case we have first to derive the optimal predictor $\varphi^{*}(t+d+1)$ of $\varphi(t+d+1)=P y(t+d+1)$, since it is a future information. It is given by (see Appendix A)

$$
\begin{aligned}
& \varphi^{*}(t+d+1) \\
& =\widetilde{C}^{-1}\left(q^{-1}\right)\left[\widetilde{F}\left(q^{-1}\right) B^{*}\left(q^{-1}\right) \underline{u}(t)+\widetilde{G}\left(q^{-1}\right) \underline{y}(t)\right],
\end{aligned}
$$

where $\widetilde{C}, \widetilde{F}$, and $\widetilde{G}$ are polynomial matrices defined in Appendix $A$ and $B^{*}\left(q^{-1}\right)=q B\left(q^{-1}\right)$.

Using (18) and (21) it is shown that the control strategy is given by (see Appendix B)

$$
\begin{aligned}
H\left(q^{-1}\right) \underline{u}(t)=\widetilde{C} & \left(q^{-1}\right) R_{w}\left(q^{-1}\right) \underline{w}(t+d+1) \\
& -\widetilde{G}\left(q^{-1}\right) \underline{y}(t),
\end{aligned}
$$

where $H\left(q^{-1}\right)=\widetilde{F}\left(q^{-1}\right) B^{*}\left(q^{-1}\right)+\widetilde{C}\left(q^{-1}\right) Q_{m}\left(q^{-1}\right)$.

\section{Mathematical Model of Earthquake Ground Motion}

The earthquake ground acceleration is modeled as a uniformly modulated nonstationary random process $[19,27]$ :

$$
\ddot{x}_{g}(t)=\psi(t) \ddot{x}_{s}(t),
$$

where $\psi(t)$ is a deterministic nonnegative envelope function and $\ddot{x}_{s}(t)$ is a stationary random process with zero mean and a Kanai-Tajimi power spectral density:

$$
\phi_{g}(\omega)=\left[\frac{1+4 \xi_{g}^{2}\left(\omega / \omega_{g}\right)^{2}}{\left(1-\left(\omega / \omega_{g}\right)^{2}\right)^{2}+4 \xi_{g}^{2}\left(\omega / \omega_{g}\right)^{2}}\right] S_{0}^{2},
$$

where $\xi_{g}, \omega_{g}$ are filter parameters and $S_{0}$ is the constant spectral density of the white noise. However, it can be shown that the velocity and displacement spectra, which are derived from the acceleration spectra described by (24), have strong singularities at zero frequency. These singularities can be removed by using high-pass filter, as suggested by CloughPenzien [19].

Using such a second high-pass filter, the Kanai-Tajimi spectrum is modified as follows to obtain the Clough-Penzien spectrum:

$$
\begin{aligned}
\phi_{c}(\omega)= & {\left[\frac{1+4 \xi_{g}^{2}\left(\omega / \omega_{g}\right)^{2}}{\left(1-\left(\omega / \omega_{g}\right)^{2}\right)^{2}+4 \xi_{g}^{2}\left(\omega / \omega_{g}\right)^{2}}\right] } \\
& \cdot\left[\frac{\left(\omega / \omega_{c}\right)^{4}}{\left(1-\left(\omega / \omega_{c}\right)^{2}\right)^{2}+4 \xi_{c}^{2}\left(\omega / \omega_{c}\right)^{2}}\right] S_{0}^{2} .
\end{aligned}
$$

A particular envelope function $\psi(t)$ given in the following will be used:

$$
\psi(t)= \begin{cases}0 & \text { for } t<0 \\ \left(\frac{t}{t_{1}}\right)^{2} & \text { for } 0 \leq t \leq t_{1} \\ 1 & \text { for } t_{1} \leq t \leq t_{2} \\ \exp \left[-a\left(t-t_{2}\right)\right] & \text { for } t \geq t_{2},\end{cases}
$$

where $t_{1}, t_{2}$, and $a$ are parameters that should be selected appropriately to reflect the shape and duration of the earthquake ground acceleration. Numerical values of parameters are $t_{1}=3 \mathrm{~s}, t_{2}=13 \mathrm{~s}, a=0.26, \xi_{g}=0.65, \omega_{g}=19 \mathrm{rad} / \mathrm{s}$, $\xi_{c}=0.6, \omega_{c}=2 \mathrm{rad} / \mathrm{s}$, and $S_{0}=0.8 \cdot 10^{-2} \mathrm{~m} / \mathrm{s}$.

The Kanai-Tajimi and Clough-Penzien ground accelerations have been simulated and are presented in Figure 2.

\section{Simulation Results}

Simulation tests are performed using a 3DOF structure with structural parameters [28]

$$
\begin{aligned}
& m_{1}=2100 \mathrm{Kg}, k_{1}=1262450 \mathrm{~N} / \mathrm{m}, \text { and } c_{1}= \\
& 3675 \mathrm{Ns} / \mathrm{m}, \\
& m_{2}=2100 \mathrm{Kg}, k_{2}=2607500 \mathrm{~N} / \mathrm{m}, \text { and } c_{2}= \\
& 10500 \mathrm{Ns} / \mathrm{m},
\end{aligned}
$$




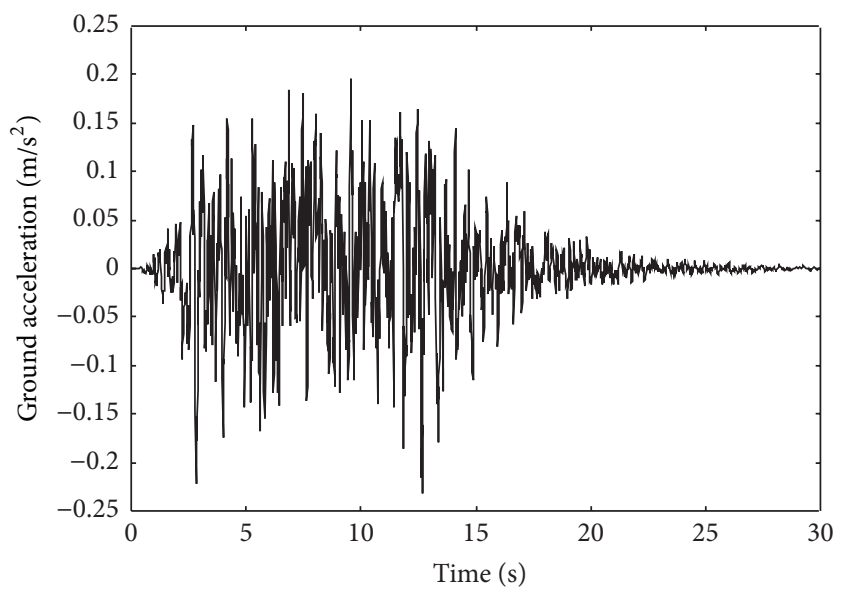

(a) Kanai-Tajimi model

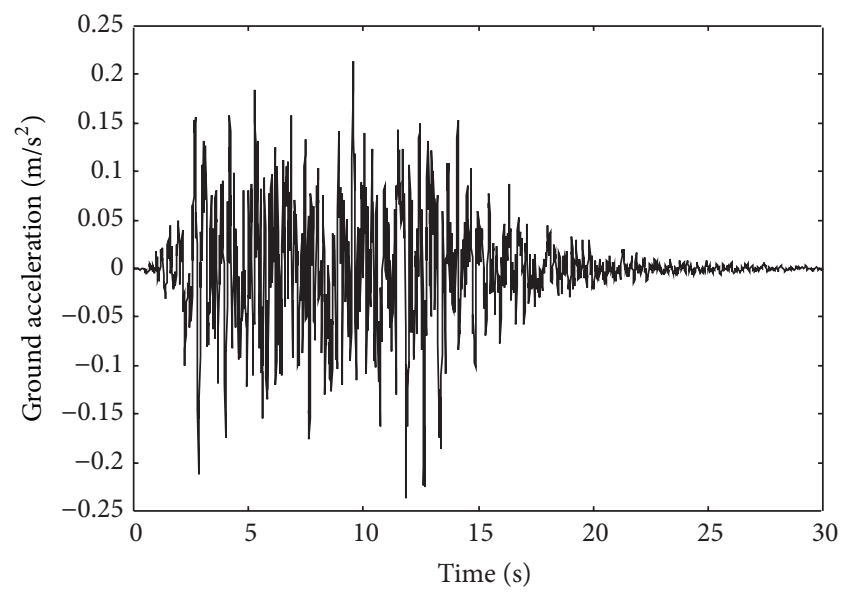

(b) Clough-Penzien model

FiguRE 2: Simulated ground accelerations.

$m_{3}=2100 \mathrm{Kg}, k_{3}=2607500 \mathrm{~N} / \mathrm{m}$, and $c_{3}=$ $10500 \mathrm{Ns} / \mathrm{m}$.

An active tendon controller is installed in every story unit and the angle of incline of the tendons with respect to the floor is $25^{\circ}$. Thus, the control force vector from the controllers is $u / \cos 25^{\circ}$. Thus, we can suppose that the force is applied at the top of each story and assumed to be activated externally by an independent power supply.

To implement the multivariable GMV algorithm, a sampling period $T_{s}=0.02 \mathrm{~s}$ is used. Parameters of the multivariable ARMAX model of the structure are given in the following:

$$
\begin{aligned}
& \bar{A}_{1}=\left[\begin{array}{ccc}
-1,225 & -0,3059 & 0 \\
-0,2906 & -0,9905 & -0,2906 \\
0 & -0,318 & -1,451
\end{array}\right], \\
& \bar{A}_{2}=\left[\begin{array}{ccc}
0,8737 & -0,1309 & 0 \\
-0,1236 & 0,8187 & -0,1236 \\
0 & -0,1354 & 0,9048
\end{array}\right], \\
& \bar{B}_{1}=\left[\begin{array}{ccc}
8,568 & -8,568 & 0 \\
0 & 8,215 & -8,215 \\
0 & 0 & 8,842
\end{array}\right] \cdot 10^{-8}, \\
& \bar{B}_{2}=\left[\begin{array}{ccc}
8,182 & -8,182 & 0 \\
0 & 7,667 & -7,667 \\
0 & 0 & 8,547
\end{array}\right] \cdot 10^{-8}, \\
& \bar{C}_{1}=\left[\begin{array}{ccc}
0,955 & 0 & 0 \\
0 & 0,933 & 0 \\
0 & 0 & 0,966
\end{array}\right] .
\end{aligned}
$$

Ponderation polynomials are

$$
\begin{aligned}
Q_{m}\left(q^{-1}\right)= & {\left[\begin{array}{ccc}
2 \cdot 10^{-7} & 0 & 0 \\
0 & 2 \cdot 10^{-7} & 0 \\
0 & 0 & 2 \cdot 10^{-7}
\end{array}\right], } \\
P\left(q^{-1}\right)= & {\left[\begin{array}{lll}
1 & 0 & 0 \\
0 & 1 & 0 \\
0 & 0 & 1
\end{array}\right]+\left[\begin{array}{ccc}
-0,5 & 0 & 0 \\
0 & -0,5 & 0 \\
0 & 0 & -0,5
\end{array}\right] q^{-1} } \\
& \cdot R_{w}=I .
\end{aligned}
$$

$P\left(q^{-1}\right)$ is the output signal filter transfer function given with $P(1)$ set to unity to ensure offset-free control. For process control, if the process output has a large overshoot to setpoint and load changes, the transfer function $P\left(q^{-1}\right)$ can be used to penalize this overshoot. The output signal filter influences both the reference tracking and the disturbance rejection properties. When it is applied, the control can be slower, the overshoots can be damped, and the changes in the manipulated variable can be suppressed.

$R_{w}$ is the reference weighting filter. Higher weighting leads to faster control (with more overshoot) and to higher control signal increments. On the other hand, Smaller weighting leads to slower control (with less overshoot) and to smaller changes in the manipulated signals. The reference signal filter does not influence the disturbance rejection or a plant/model mismatch. When it is applied, the control can be slower, overshoots can be damped, and the changes in the manipulated variable can be suppressed.

$Q_{m}$ is the weighting of the control increments. Higher weighting leads to slower control (with less overshoot) and to smaller changes in the manipulated variable. However, smaller weighting leads to faster control (with more overshoot) and to bigger changes in the manipulated variable. 

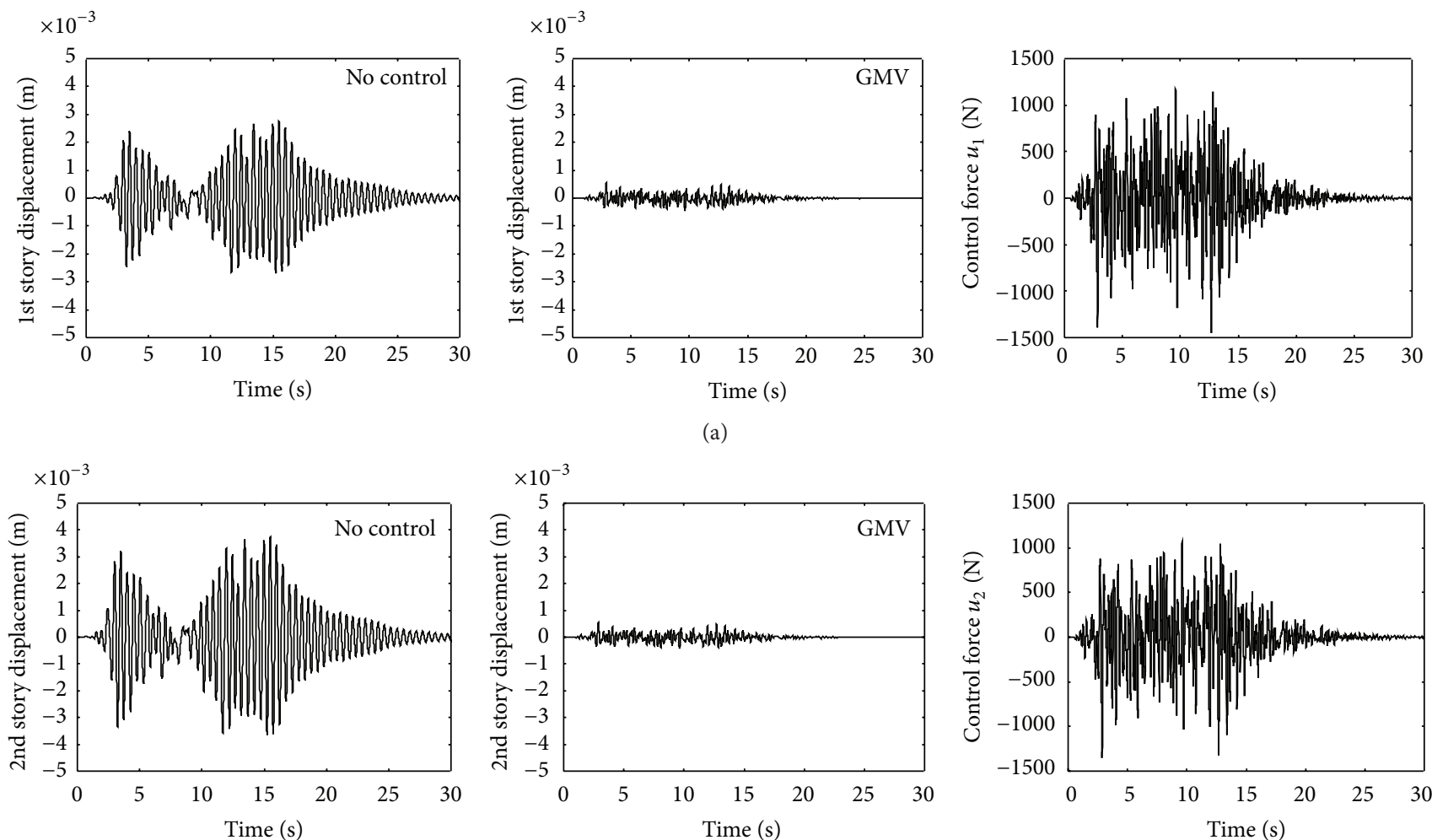

(a)
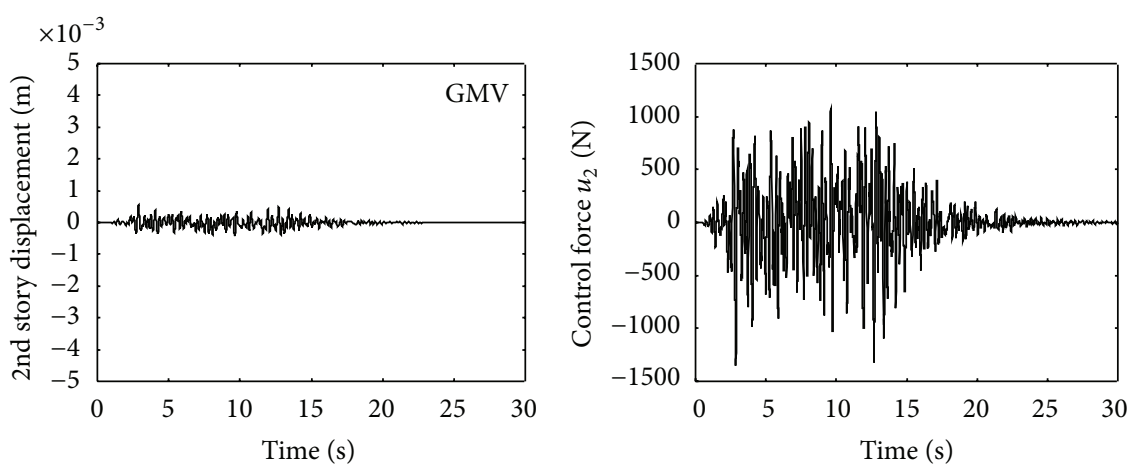

(b)
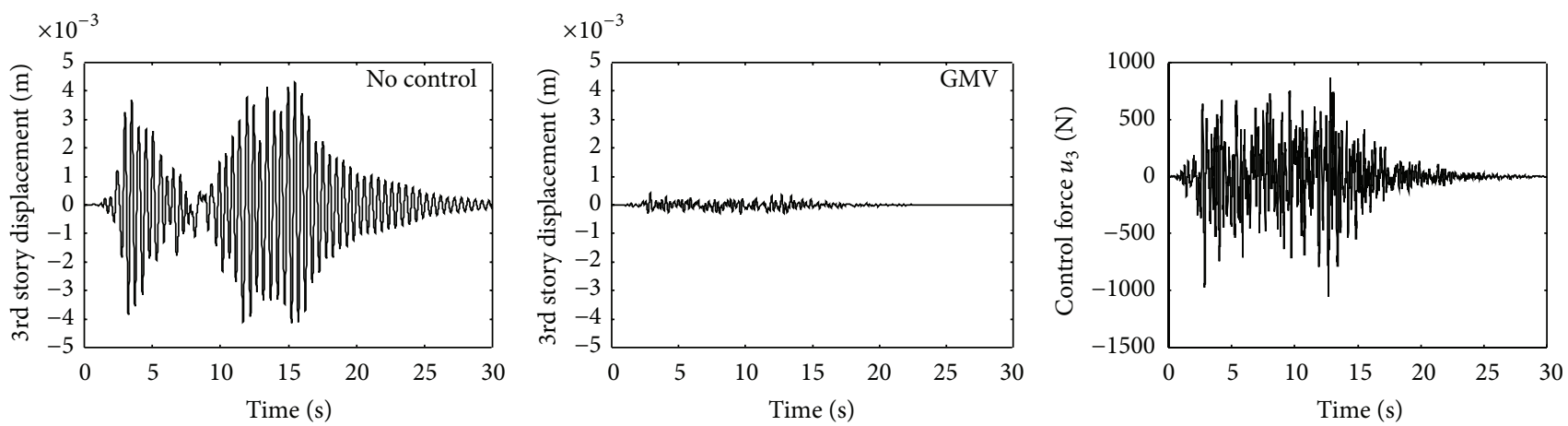

(c)

FiguRE 3: Structural response to Kanai-Tajimi ground acceleration. (a) 1st story, (b) 2nd story, and (c) 3rd story.

Table 1 gives the output variance for each story.

Responses of the structure to Kanai-Tajimi and CloughPenzien excitation models are shown in Figures 3 and 4, respectively.

Generalized Minimum of Variance (GMV) control strategy for MDOF structure using Kanai-Tajimi and CloughPenzien seismic models is presented in Figures 3 and 4. GMV algorithm is based on the minimization of a quadratic cost function, and the solution of the Diophantine equation is required. We compare the displacement responses without control and the ones controlled by the GMV algorithm. The control parameters are chosen to give the optimal performances according to the effect of each parameter discussed $\left(P\left(q^{-1}\right), R_{w}\right.$, and $\left.Q_{m}\right)$. The results show a considerable reduction of the structural vibration under the applied seismic load.
TABLE 1: Output variance.

\begin{tabular}{lcc}
\hline & $\begin{array}{c}\text { Kanai-Tajimi excitation model } \\
\text { No control }\end{array}$ & GMV control \\
\hline 1st story & $8,4792 \cdot 10^{-7}$ & $1,4868 \cdot 10^{-8}$ \\
2nd story & $1,5669 \cdot 10^{-6}$ & $1,4473 \cdot 10^{-8}$ \\
3rd story & $2,0394 \cdot 10^{-6}$ & $7,9022 \cdot 10^{-9}$ \\
\hline \multicolumn{3}{c}{ Clough-Penzien excitation model } \\
1st story & No control & $\mathrm{GMV} \mathrm{control}$ \\
2nd story & $8,5882 \cdot 10^{-7}$ & $1,4698 \cdot 10^{-8}$ \\
3rd story & $1,5872 \cdot 10^{-6}$ & $1,4287 \cdot 10^{-8}$ \\
\hline
\end{tabular}

The proposed control strategy has proved the considerable efficiency for the mitigation of the structural response under 

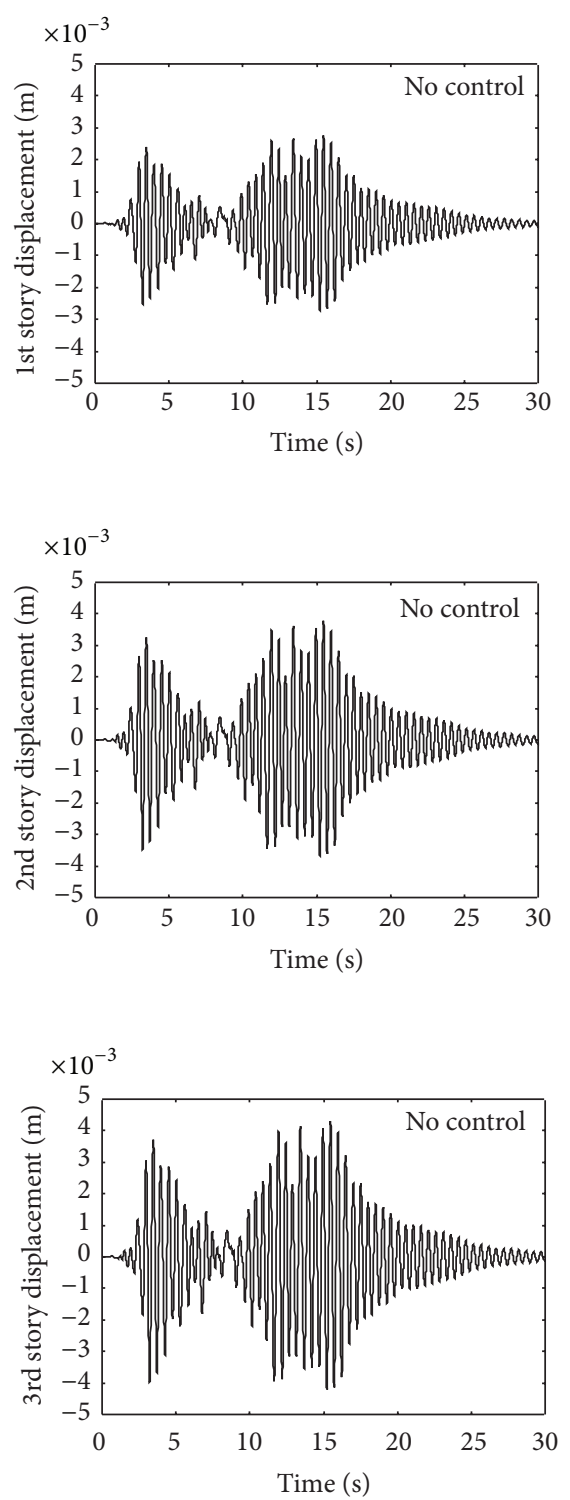

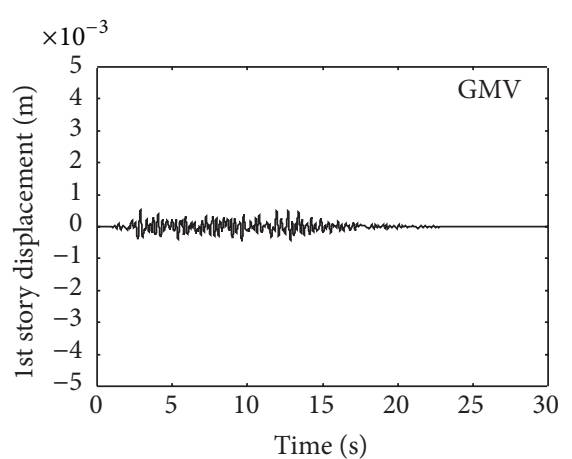

(a)

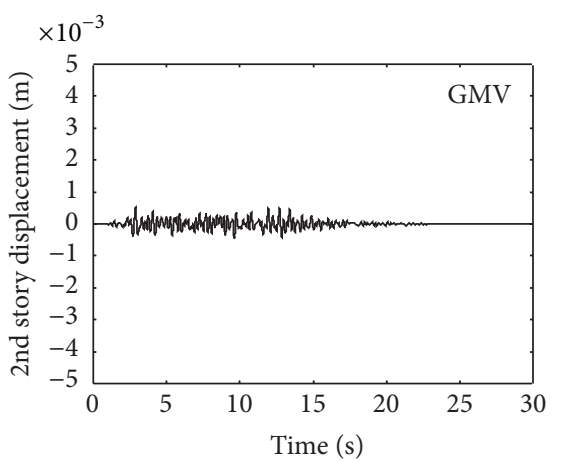

(b)

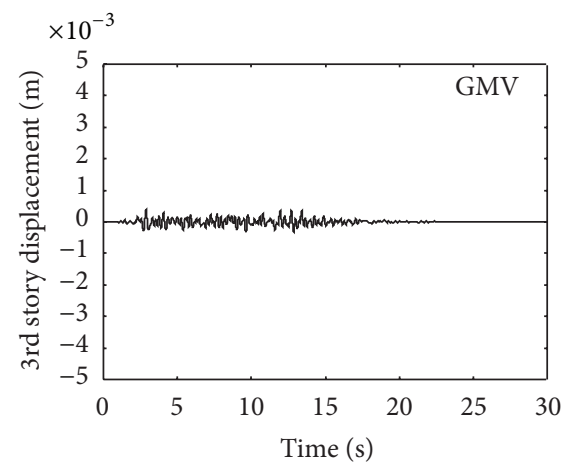

(c)
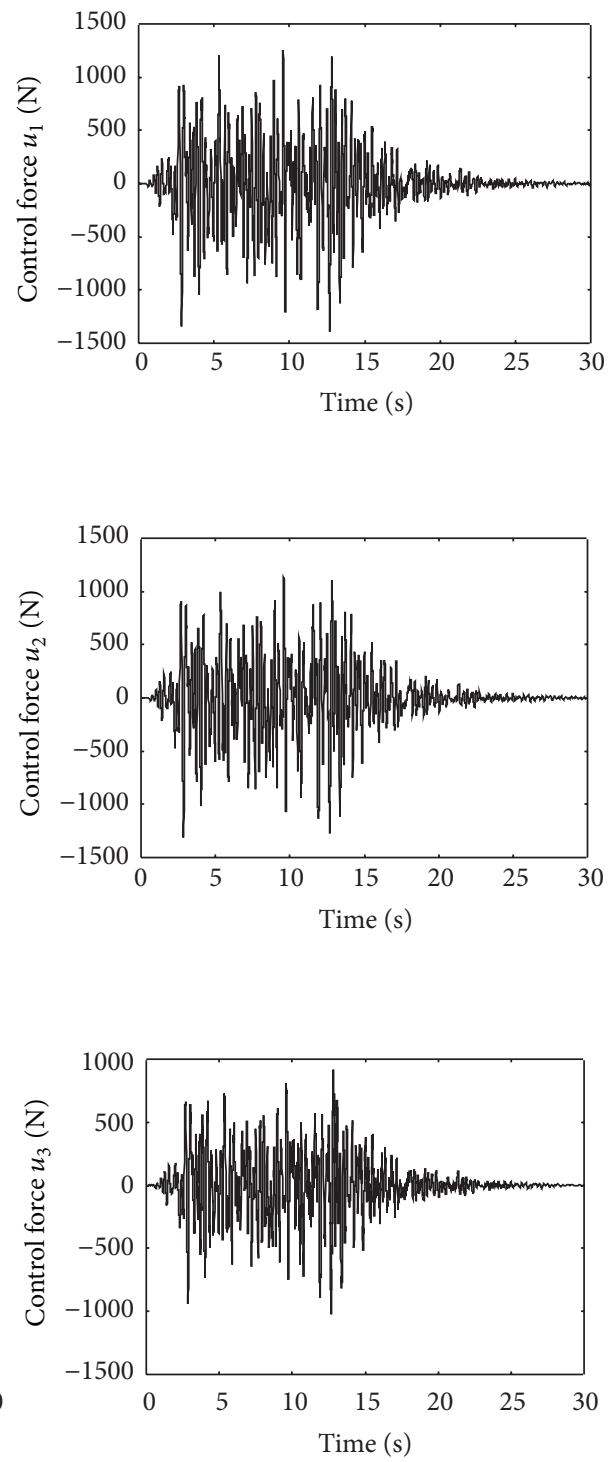

Figure 4: Structural response to Clough-Penzien ground acceleration. (a) 1st story, (b) 2nd story, and (c) 3rd story.

seismic ground motion. The ARMAX model presents an interesting form to formulate a MDOF structural model for a control perspective in the earthquake engineering problem.

In the last decade, several works have shown the effectiveness of the active control strategies in the earthquake engineering problem. Guenfaf and Allaoua [29] have investigated a flux oriented control of Active Mass Damper (AMD) induction motor for buildings under seismic ground motion. The LQR control algorithm has been used for displacement reduction of the structure. The simulation results show that the torque supplied by the induction motor pursuits its reference provided by the LQR control algorithm. Significant reductions of $65 \%$ and $78 \%$, respectively, in the roof acceleration and roof displacement have been reached. Xu et al. [30] have proposed a real-time Active Mass Damper (AMD) subsystem testing method, which has been applied to verify the performance of an innovative AMD control system driven by a linear motor. Yamamoto and Sone [31] have presented the feasibility, stability, and reliability of the integrated AMD subsystem, including hardware and software. The main purpose of an AMD that was installed in a high-rise building in Tokyo is to maintain human comfort in two horizontal directions under the strong earthquakes. The control performance of the AMD was confirmed. The AMD controlled the building acceleration such that it was $60 \%$ of its maximum derivation during the Tohoku earthquake 2011. Ikeda [32] has presented the practical applications and verification of the active and the semiactive control strategy for the structural control problem. Practical applications of active and semiactive vibration control of buildings in Japan are reported, and the installation tendency is described in relation to research phases of structural control. 
Control verification methods are introduced to link structural control with monitoring and system identification. The state of the art shows that the use of structural control and its related technologies have been expanding in the last two decades since the late Professor Kobori suggested the importance of active structural control in the civil engineering field in the mid-1980s.

\section{Conclusions}

This paper investigated GMV control technique applied to earthquake excited MDOF structures. Our control approach was developed and presented based on the ARMAX model calculation. The multivariable GMV have demonstrated good performances and the structural responses are significantly reduced. The control strategy used in this paper is an extension to the SDOF case of the classical GMV algorithm. It is designed for the structure as a multivariable system.

The multivariable GMV algorithm is an efficient control technique with a well-established theoretical development. However, it has the disadvantage of the great amount of calculations and matrix manipulation especially in the case of tall buildings with a large number of degrees of freedom. Nevertheless, it takes into account the coupling terms between different storey buildings, and this gives more realistic results due to the nonlinear nature of this coupling terms.

\section{Appendix}

\section{A. Derivation of the Optimal Predictor for MIMO Systems}

We first introduce the polynomial matrix equation:

$$
\bar{C}\left(q^{-1}\right)=A\left(q^{-1}\right) F\left(q^{-1}\right)+q^{-(d+1)} G\left(q^{-1}\right),
$$

where

$$
\begin{aligned}
& F\left(q^{-1}\right)=F_{0}+F_{1} q^{-1}+\cdots+F_{d} q^{-d} \\
& G\left(q^{-1}\right)=G_{0}+G_{1} q^{-1}+\cdots+G_{n g} q^{-n g}
\end{aligned}
$$

where $n g=\max [l+n p-d-1, n-1]$ and $n p=\operatorname{deg}\left[P\left(q^{-1}\right)\right]$,

$$
\begin{aligned}
\bar{C}\left(q^{-1}\right) & =\bar{P}\left(q^{-1}\right) C\left(q^{-1}\right), \\
\bar{A}\left(q^{-1}\right) P\left(q^{-1}\right) & =\bar{P}\left(q^{-1}\right) A\left(q^{-1}\right),
\end{aligned}
$$

where $\operatorname{det} \bar{A}\left(q^{-1}\right)=\operatorname{det} A\left(q^{-1}\right)$ and $\bar{A}(0)=I$.

There exist nonunique matrices $\bar{F}$ and $\bar{G}$ verifying

$$
\bar{F}\left(q^{-1}\right) G\left(q^{-1}\right)=\bar{G}\left(q^{-1}\right) F\left(q^{-1}\right),
$$

where $\operatorname{det} \bar{F}\left(q^{-1}\right)=\operatorname{det} F\left(q^{-1}\right)$.

We introduce the polynomial matrix $\widetilde{C}$ :

$$
\widetilde{C}\left(q^{-1}\right)=\bar{F}\left(q^{-1}\right) A\left(q^{-1}\right)+q^{-(d+1)} \widetilde{G}\left(q^{-1}\right) .
$$

From (12), (A.4), (A.3), (A.5), and (A.6) we demonstrate that

$$
\begin{aligned}
\widetilde{C}\left(q^{-1}\right) P\left(q^{-1}\right)= & \widetilde{F}\left(q^{-1}\right) A\left(q^{-1}\right) \\
& +q^{-(d+1)} \widetilde{G}\left(q^{-1}\right), \\
\widetilde{C}\left(q^{-1}\right) F\left(q^{-1}\right)= & \widetilde{F}\left(q^{-1}\right) C\left(q^{-1}\right),
\end{aligned}
$$

where $\widetilde{F}\left(q^{-1}\right)=\bar{F}\left(q^{-1}\right) \bar{P}\left(q^{-1}\right)$ and $\widetilde{G}\left(q^{-1}\right)=\bar{G}\left(q^{-1}\right) P\left(q^{-1}\right)$.

Equation (18) can be written as

$$
\begin{aligned}
A\left(q^{-1}\right) \underline{y}(t+d+1)= & B^{*}\left(q^{-1}\right) \underline{u}(t) \\
& +C\left(q^{-1}\right) \underline{e}(t+d+1) .
\end{aligned}
$$

Multiplying (A.8) by $\widetilde{F}$ and after some calculations using (A.7) we obtain

$$
\begin{aligned}
& \varphi(t+d+1)=P\left(q^{-1}\right) \underline{y}(t+d+1)=\widetilde{C}^{-1}\left(q^{-1}\right) \\
& \cdot\left\lfloor\widetilde{G}\left(q^{-1}\right) \underline{y}(t)+\widetilde{F}\left(q^{-1}\right) B^{*}\left(q^{-1}\right) \underline{u}(t)\right\rfloor \\
& +F\left(q^{-1}\right) \underline{e}(t+d+1) .
\end{aligned}
$$

We remark that $F\left(q^{-1}\right) e(t+d+1)=F_{0} e(t+d+1)+F_{1} e(t+d)+$ $\cdots+F_{d} e(t+1)$ is the future information. Thus, the optimal predictor of $\varphi(t+d+1)$ is given by

$$
\begin{aligned}
& \varphi^{*}(t+d+1)=\widetilde{C}^{-1}\left(q^{-1}\right) \\
& \cdot\left\lfloor\widetilde{G}\left(q^{-1}\right) \underline{y}(t)+\widetilde{F}\left(q^{-1}\right) B^{*}\left(q^{-1}\right) \underline{u}(t)\right\rfloor .
\end{aligned}
$$

\section{B. Derivation of the GMV Control for MIMO Systems}

Using (A.10), the criterion to be minimized (20) becomes

$$
\begin{aligned}
J= & E\left[\| \varphi^{*}(t+d+1)-R_{w}\left(q^{-1}\right) \underline{w}(t+d+1)\right. \\
& \left.+F\left(q^{-1}\right) \underline{e}(t+d+1)\left\|^{2}+\right\| Q_{m}^{\prime}\left(q^{-1}\right) \underline{u}(t) \|^{2}\right] .
\end{aligned}
$$

The term $F\left(q^{-1}\right) \underline{e}(t+d+1)$ is uncorrelated with $\underline{u}(t-i), \underline{w}(t-i)$, and $\underline{y}(t-i)$ for $0 \leq i \leq t$. Thus, $J$ can be written as

$$
\begin{aligned}
J= & E\left[\left\|\varphi^{*}(t+d+1)-R_{w}\left(q^{-1}\right) \underline{w}(t+d+1)\right\|^{2}\right. \\
& \left.+\left\|Q_{m}^{\prime}\left(q^{-1}\right) \underline{u}(t)\right\|^{2}\right] \\
& +E\left[\left\|F\left(q^{-1}\right) \underline{e}(t+d+1)\right\|^{2}\right] .
\end{aligned}
$$

The minimum of $J$ is found by forming the gradient of $J$ with respect to $\underline{u}(t)$ :

$$
\begin{aligned}
& \frac{\partial J}{\partial \underline{u}(t)}=2 E\left[\left(\frac{\partial \varphi^{*}(t+d+1)}{\partial \underline{u}(t)}\right)^{T}\right. \\
& \cdot\left(\varphi^{*}(t+d+1)-R_{w}\left(q^{-1}\right) \underline{w}(t+d+1)\right) \\
& \left.\quad+Q_{m}^{\prime}(0)^{T} Q_{m}^{\prime}\left(q^{-1}\right) \underline{u}(t)\right]=0
\end{aligned}
$$


or

$$
\begin{gathered}
\varphi^{*}(t+d+1)-R_{w}\left(q^{-1}\right) \underline{w}(t+d+1) \\
+Q_{m}\left(q^{-1}\right) \underline{u}(t)=0,
\end{gathered}
$$

where $Q_{m}\left(q^{-1}\right)=\left[\left(P_{0} B_{1}\right)^{T}\right]^{-1} Q_{m}^{\prime}(0)^{T} Q_{m}^{\prime}\left(q^{-1}\right)$.

Substituting (A.10) into (B.4), we obtain the control strategy:

$$
\begin{aligned}
& H\left(q^{-1}\right) \underline{u}(t)= \widetilde{C} \\
&\left(q^{-1}\right) R_{w}\left(q^{-1}\right) \underline{w}(t+d+1) \\
&-\widetilde{G}\left(q^{-1}\right) \underline{y}(t),
\end{aligned}
$$

where $H\left(q^{-1}\right)=\widetilde{F}\left(q^{-1}\right) B^{*}\left(q^{-1}\right)+\widetilde{C}\left(q^{-1}\right) Q_{m}\left(q^{-1}\right)$.

\section{Competing Interests}

The authors declare that there are no competing interests regarding the publication of this paper.

\section{References}

[1] G. Mei, A. Kareem, and J. C. Kantor, "Model predictive control of structures under earthquakes using acceleration feedback," Journal of Engineering Mechanics, vol. 128, no. 5, pp. 574-585, 2002.

[2] S. Purohit and N. K. Chandiramani, "Optimal static output feedback control of a building using an MR damper," Structural Control and Health Monitoring, vol. 18, no. 8, pp. 852-868, 2011.

[3] A. Shafieezadeh, K. Ryan, and Y. Chen, "Fractional order filter enhanced LQR for seismic protection of civil structures," Journal of Computational and Nonlinear Dynamics, vol. 3, no. 2, Article ID 021404, 2008.

[4] S.-G. Wang, "LQG- $\alpha$ control and its simulations for structural benchmark problems against winds and earthquakes," in Proceedings of the 42nd IEEE Conference on Decision and Control, pp. 6572-6577, December 2003.

[5] L. Guenfaf and S. Allaoua, "Linear quadratic AMD controller with an observer for buildings under seismic ground motion," in Proceedings of the 13th International Conference on Control, Automation and Systems (ICCAS '13), pp. 1559-1564, IEEE, Gwangju, Republic of Korea, October 2013.

[6] L. Guenfaf and S. Allaoua, "Optimal choice of actuator for AMD linear quadratic controller," Journal of Electrical and Control Engineering, vol. 3, no. 3, pp. 31-38, 2013.

[7] L. Guenfaf, S. Allaoua, M. Djebiri, M. S. Boucherit, and F. Boudjema, "Generalized minimum variance gain scheduling controller for nonlinear structural systems under seismic ground motion," Journal of Electrical Systems, vol. 8, no. 4, pp. 472-480, 2012.

[8] T. E. Saaed Alqado, G. Nikolakopoulos, and J.-E. Jonasson, "Comfort level identification for irregular multi-storey building," Automation in Construction C, vol. 50, pp. 40-49, 2015.

[9] L. Guenfaf and M. Azira, "ARMAX model calculation for structures under seismic ground motion including soil-structure interaction," Journal of Electrical and Control Engineering, vol. 4, no. 1, pp. 8-15, 2013.

[10] S. Paul, W. Yu, and X. Li, "Recent advances in bidirectional modeling and structural control," Shock and Vibration, vol. 2016, Article ID 6275307, 17 pages, 2016.
[11] H. Qian, H. Li, G. Song, and W. Guo, "Recentering shape memory alloy passive damper for structural vibration control," Mathematical Problems in Engineering, vol. 2013, Article ID 963530, 13 pages, 2013.

[12] Y. Si, H. R. Karimi, and H. Gao, "Modeling and parameter analysis of the OC3-hywind floating wind turbine with a tuned mass damper in nacelle," Journal of Applied Mathematics, vol. 2013, Article ID 679071, 10 pages, 2013.

[13] L. Guenfaf, M. Djebiri, M. S. Boucherit, and F. Boudjema, "Generalized minimum variance control for buildings under seismic ground motion," Earthquake Engineering and Structural Dynamics, vol. 30, no. 7, pp. 945-960, 2001.

[14] Y. Lei, D.-T. Wu, and S.-Z. Lin, "Integration of decentralized structural control and the identification of unknown inputs for tall shear building models under unknown earthquake excitation," Engineering Structures, vol. 52, pp. 306-316, 2013.

[15] M. Athans, "The role and use of the stochastic linear-quadraticGaussian problem in control system design," IEEE Transactions on Automatic Control, vol. AC-16, pp. 529-552, 1971.

[16] D. W. Clarke, "Introduction to self tuning controller," in Self Tuning and Adaptive Control: Theory and Application, vol. 15 of IEE Control Engineering Series, Peter Pregrinus, 1981.

[17] D. W. Clarke, "Self-tuning control of nonminimum-phase systems," Automatica, vol. 20, no. 5, pp. 501-517, 1984.

[18] K. J. Åström, Introduction to Stochastic Control Theory, vol. 70 of Mathematics in Science and Engineering, Academic Press, New York, NY, USA, 1970.

[19] R. W. Clough and J. Penzien, Dynamics of Structures, McGrawHill, New York, NY, USA, 1993.

[20] L. Dugard, G. C. Goodwin, and X. Xianya, "The role of the interactor matrix in multivariable stochastic adaptive control," Automatica, vol. 20, no. 5, pp. 701-709, 1984.

[21] M.-H. Liu and W. Lin, "Pole assignment self-tuning controller for robotic manipulators," International Journal of Control, vol. 46, no. 4, pp. 1307-1317, 1987.

[22] M.-H. Liu and W. Lin, "Multivariable self-tuning control with decoupling for robotic manipulator," IEE Proceedings D: Control Theory and Applications, vol. 135, no. 1, pp. 43-48, 1988.

[23] A. Mohamed and G. Lakhdar, "GMV Control algorithm for structures under recorded strong earthquakes including soil characteristics," in Proceedings of the 2015 15th International Conference on Control, Automation and Systems (ICCAS '15), pp. 1687-1692, Busan, Republic of Korea, October 2015.

[24] U. Borison, "Self-tuning regulators for a class of multivariable systems," Automatica, vol. 15, no. 2, pp. 209-215, 1979.

[25] H. N. Koivo, "A multivariable self-tuning controller," Automatica, vol. 16, no. 4, pp. 351-366, 1980.

[26] S.-J. Lang, X.-Y. Gu, and T.-Y. Chai, "A Multivariable generalized self-tuning controller with decoupling design," IEEE Transactions on Automatic Control, vol. AC-31, no. 5, pp. 474-477, 1986.

[27] J. N. Yang, A. Akbarpour, and P. Ghaemmaghami, "New optimal control algorithms for structural control," Journal of Engineering Mechanics, vol. 113, no. 9, pp. 1369-1386, 1987.

[28] A. G. Chassiakos and S. F. Masri, "Modelling unknown structural systems through the use of neural networks," Earthquake Engineering and Structural Dynamics, vol. 25, no. 2, pp. 117-128, 1996.

[29] L. Guenfaf and S. Allaoua, "Flux oriented control of Active Mass Damper induction motor for buildings under seismic excitation," in Proceedings of the 15th International Conference on Control, Automation and Systems (ICCAS '15), pp. 1676-1681, BEXCO, Busan, Korea, October 2015. 
[30] H. Xu, C. Zhang, H. Li, and J. Ou, "Real-time hybrid simulation approach for performance validation of structural active control systems: a linear motor actuator based active mass driver case study," Structural Control and Health Monitoring, vol. 21, no. 4, pp. 574-589, 2014.

[31] M. Yamamoto and T. Sone, "Behavior of active mass damper (AMD) installed in high-rise building during 2011 earthquake off Pacific coast of Tohoku and verification of regenerating system of AMD based on monitoring," Structural Control and Health Monitoring, vol. 21, no. 4, pp. 634-647, 2014.

[32] Y. Ikeda, "Active and semi-active vibration control of buildings in Japan-practical applications and verification," Structural Control and Health Monitoring, vol. 16, no. 7-8, pp. 703-723, 2009. 


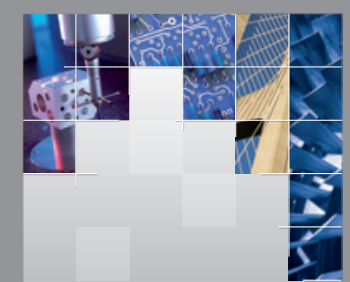

\section{Enfincering}
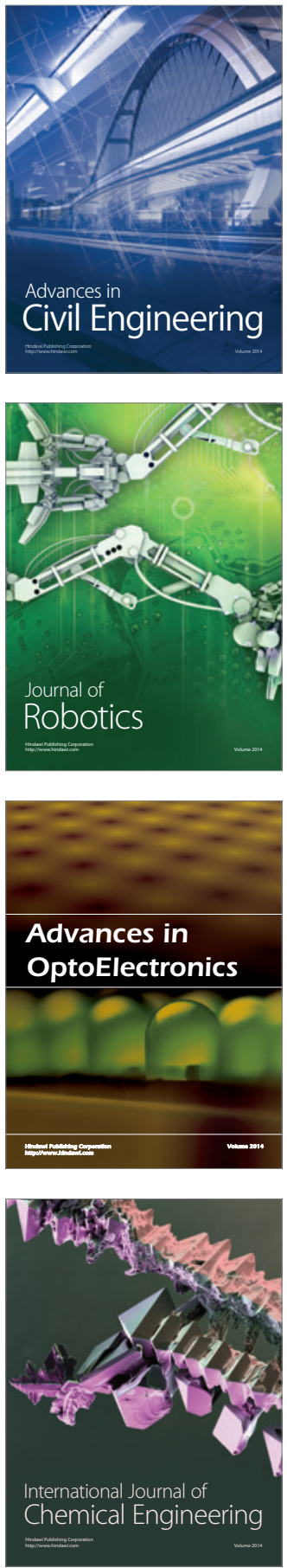

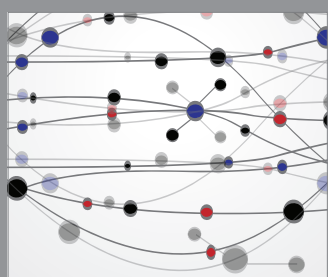

The Scientific World Journal

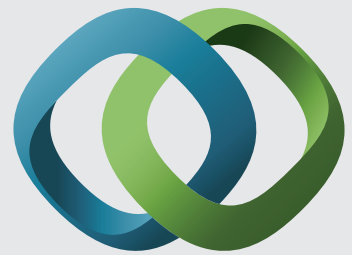

\section{Hindawi}

Submit your manuscripts at

http://www.hindawi.com
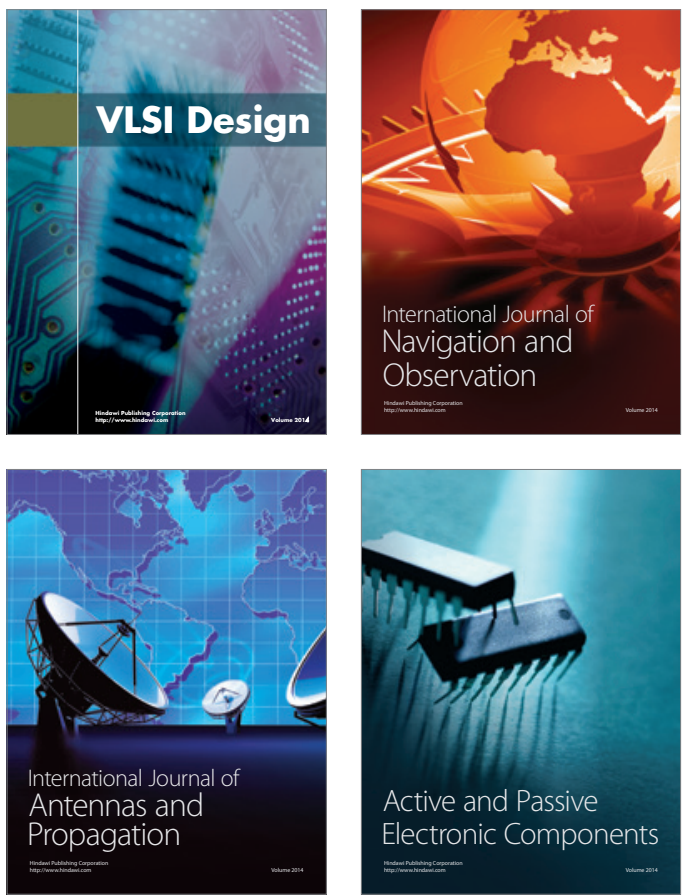
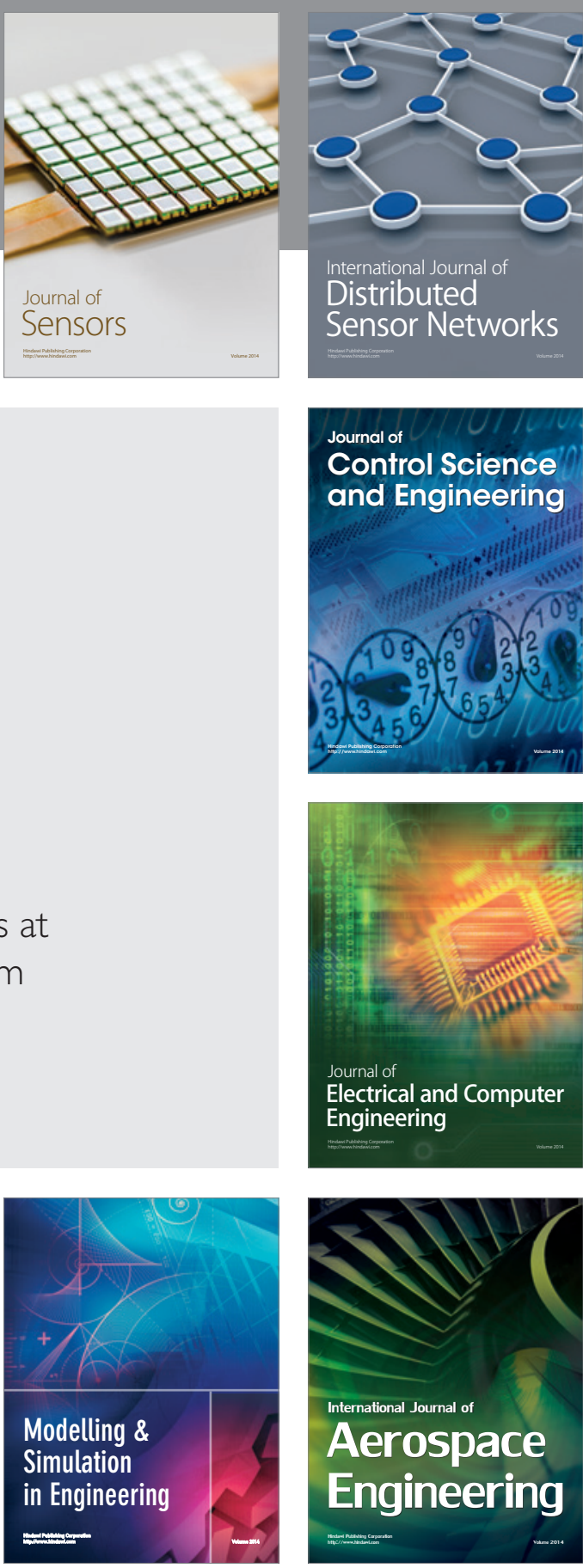

International Journal of

Distributed

Sensor Networks

Journal of

Control Science

and Engineering
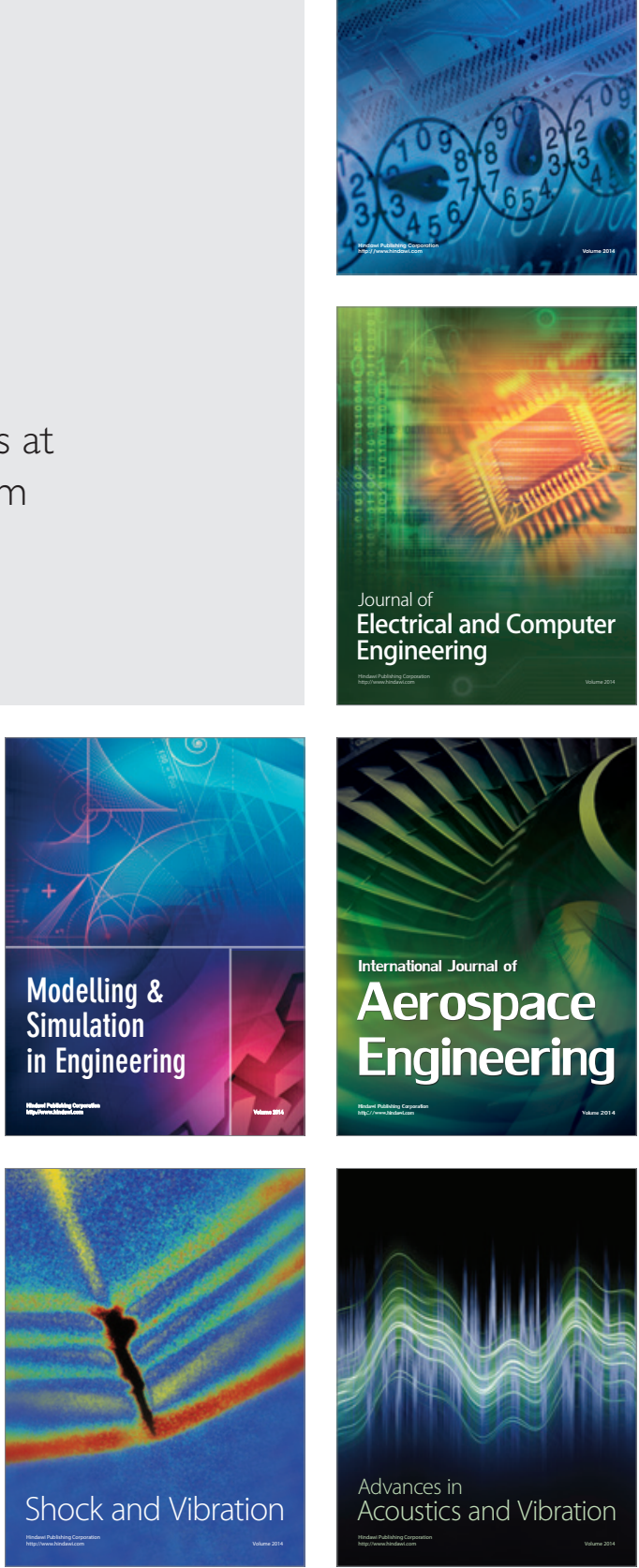